\title{
Mechanical Behaviour of Adhesive Joint under Tensile and Shear Loading
}

\author{
Xu JIANG \\ PhD student \\ TUDelft \\ Delft, the Netherlands \\ xu.jiang@tudelft.nl
}

\author{
M.H. KOLSTEIN \\ Associate Professor \\ TUDelft \\ Delft, the Netherlands \\ M.H.Kolstein@tudelft.nl
}

\author{
F.S.K. BIJLAARD \\ Professor \\ TUDelft \\ Delft, the Netherlands \\ F.S.K.Bijlaard@tudelft.nl
}

\section{Summary}

Due to various advantages of Fibre-Reinforced Polymer (FRP) decks, the FRP to steel composite bridge system is being increasingly used in new bridge structures as well as rehabilitation projects for old bridges. This paper focuses on the mechanical behaviours and failure modes of the adhesively-bonded joins between FRP sandwich decks and steel girders. The adhesively-bonded joints were experimentally investigated under tensile and shear loading. Further comparison on failure modes confirmed that the surface pretreatment can improve the bonding quality between FRP composites and adhesive layer, and correspondingly increase the load-carrying capacity of adhesive joints.

Keywords: FRP deck; steel girder; composite bridge; adhesively-bonded joint; tensile and shear loading.

\section{Introduction}

Fibre Reinforced Polymer (FRP) bridge decks (Fig.1) are increasingly implemented in practice for rehabilitation of existing bridges and also for new bridge constructions, which is due to the
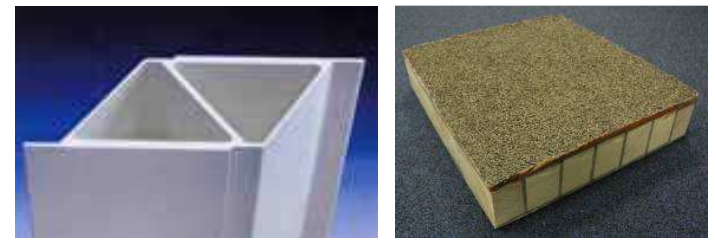

(a) Cellular FRP deck (b) Sandwich FRP deck Fig. 1. FRP bridge decks remarkable advantages of FRP decks: lightweight of bridge superstructures, the ease of installation, minimum traffic disturbing, large tolerance for environmental corrosion, long service life time, as well as low maintenance cost. To be cost-effective, the FRP decks are commonly supported by longitudinal main girders made of either steel, prestressed concrete or FRP composites [1-4]. In Knippers's research [1], the FRP-deck-to-steel-beam composite bridge was employed as a flyover across the federal road B3 in Germany. The high durability of FRP composites and the fast assembly of the bridge were decisive factors for this application. Sebastian [2] investigated the load response due to local and global indeterminacies of cellular FRP deck bridges, where the test data show a $25 \%$ asymmetry of the deck's local longitudinal strains and rapid transverse attenuation of these strains away from the loading location.

Between the FRP decks and steel girders, adhesively bonding technique is usually employed as a preferable connection method, since it can reduce construction time, save weight by eliminating fasteners, introduce more uniform load transfer and provide better long-term performance. Regarding to the adhesively-boned joint, lots of researches focus on mechanical behaviours of adhesively-bonded joints have been conducted in aerospace engineering, but the results cannot be directly inherited to civil infrastructures, due to the essential differences: bond geometries (adhesive and adherend thicknesses), fabrication processes, loading, curing conditions and service environment. Recently, some researches [5-7] were conducted for civil engineering applications, focusing on the mechanical performance of adhesively bonded single-lap joints and double-lap joints. These adhesive joints composed of pultruded GFRP composite profiles glued by epoxy adhesives. Parametric studies were conducted experimentally and numerically on the overlap length, the adhesive layer thickness, the adherend thickness and the degree of chamfering of the adherends. The results indicated that the combination of local through-thickness tensile (peeling) and shear stresses was the most severe stress-state and usually initiated the failures in adhesive fillet and in the outer fiber-mat layers of the adherends below the joint edges. Unfortunately the technical background and researches on the adhesively-bonded joins between FRP bridge decks and longitudinal main girders have not been documented adequately in literature. This paper focus on 
the adhesively-bonded joints between FRP sandwich decks and steel girders. A tensile-shear loading device was designed with the adaptability to provide the combination of tensile and shear loads in six different ratios. The mechanical behaviours and failure modes of adhesively-bonded joints under tensile and shear loading were investigated experimentally, considering the influence of surface pretreatment on FRP sandwich decks and steel girders.

\section{Tensile-shear Loading Device}

Generally, as shown in Fig.2, there are three typical stress states for the adhesive joint between FRP decks and steel girders:

1) shear stress $\tau$ : due to the composite action between FRP decks and steel girders in the longitudinal direction of bridge, the decks and steel girders tend to bend together to carry the traffic load. Thus, the adhesive joints are under the shear stress condition to transfer the loading from FRP decks to steel beams, as shown in Fig. 2a);

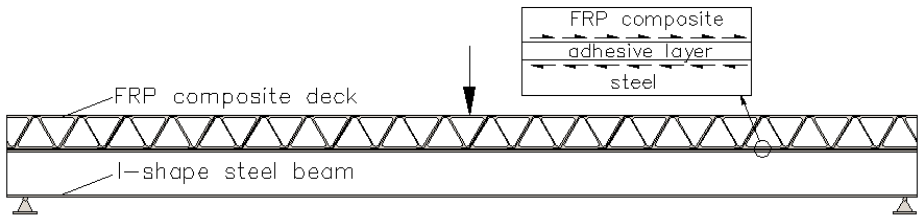

a) Shear stress in the longitudinal direction

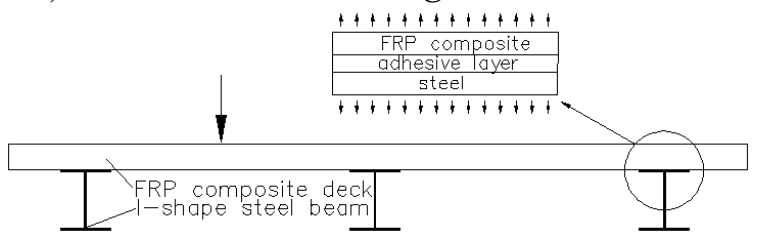

b) Tensile stress in the transverse direction
2) tensile stress $\sigma$ : in the transverse direction of bridge, loading on other traffic lanes causes up-lift forces on adhesive joints, which results in tensile stress, as shown in Fig. 2b);

3) combination of the above two stress states with different ratios of contributions from tensile stress state and shear stress state.

Depending on the aforementioned three stress states, a smart loading device was needed for providing tensile loading, shear loading and combination of both simultaneously.

The adhesively-bonded joint between FRP deck and steel girder was extracted for experimental investigation as shown in Fig. 3. A $190 \mathrm{~mm} \times 90 \mathrm{~mm}$ piece of FRP sandwich bridge deck was adhesively bonded to the convex steel support. In the middle of sandwich deck, it was Balsa SB150 with thickness of $38.1 \mathrm{~mm}$, which is a core material produced

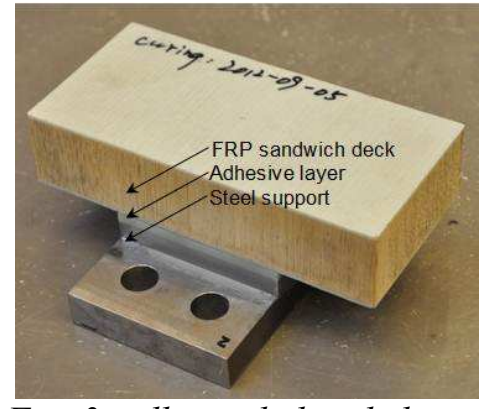

Fig. 3. adhesively bonded joint from certified kiln-dried balsa wood in the 'end-grain' configuration. The surface layers were three plies of $0.94 \mathrm{~mm}$ EQX1200, which are the glass-fibre reinforced laminated polymer composites ( $54 \%$ glass content by weight). The sandwich profiles were manufactured by resin vacuum infusion. The gluing of FRP sandwich deck to steel support was executed under the laboratory environment and cured at room temperature, which was comparable to the working condition in the construction site. The nominal thickness of $90 \mathrm{~mm} \times 90 \mathrm{~mm}$ adhesive layer was controlled to be $6 \mathrm{~mm}$ using spacers. The dimensions of adhesive joints were determined depending on the actual conditions of composite bridges as well as limitations of loading equipment. The tested adhesive joint was kept as small as possible to make it easily movable and independent of large and complicated experimental facilities.

In order to fix the adhesive joint to the loading system, some accessorial components were designed as shown in Fig. 4. The steel support was dug with 4 holes to be connected to the bottom steel block by bolts. For the sandwich decks, no hole was proposed, since the discontinued part in decks will cause more stress distribution distortion, which was not actual in applications of composite bridges. To fix the sandwich deck part, it was designed to be fastened by two purple L-shape steel plates through four bolts to the top steel block, as shown in Fig. 4a). While the steel support was fastened directly through four bolts to the bottom steel block, as shown in Fig.4b). The two steel blocks were fastened to circular steel plates via 8 bolts, as shown in Fig. 4c). The circular steel plates were separated into two pieces. Part of the central area of circular steel plates were cut off to save some 


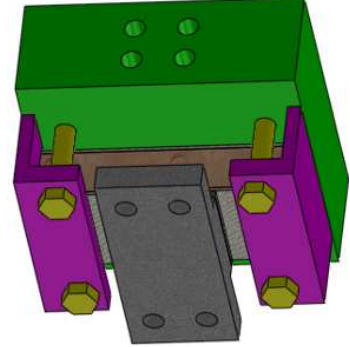

a) Deck fixed configuration

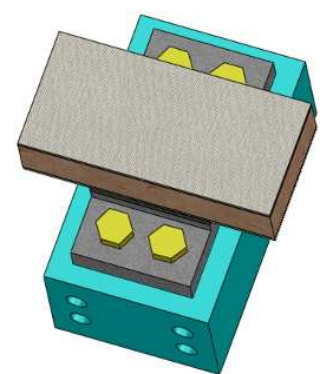

b) Steel support fixed configuration

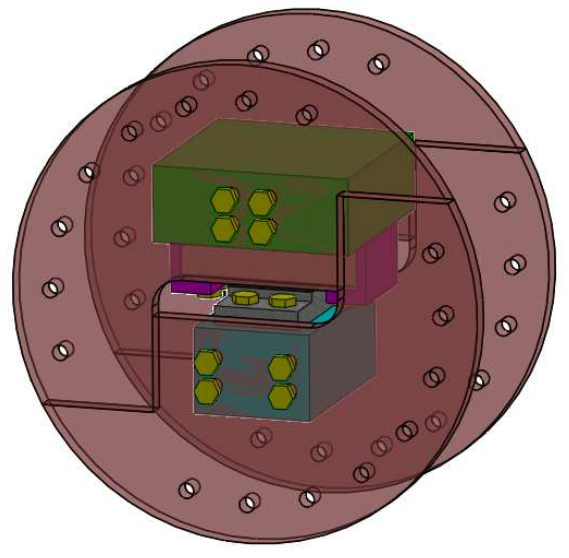

c) Whole loading system
Fig. 4. Tensile-shear loading device of $200 \mathrm{kN}$ in tension, being controlled by the INSTRON 8400 controller. The whole tensile-shear device was loaded by jacks through two hinged joints, which could avoid the additional bending moment due to the eccentric loading from specimen misalignment. The quasi-static experiments

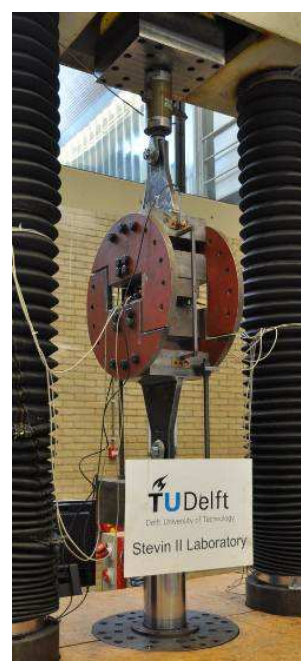

a) tensile loading

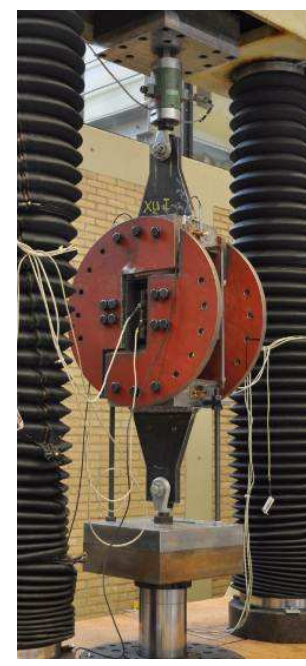

b) shear loading
Fig. 5 Experimental set-up

space for assignment of displacement sensors. Three bolts were employed to transfer loading uniformly. By loading the different angles of circular steel plates, the specific stress-state can be achieved in the adhesive joint, such as pure tension, pure shear and combination of both.

Correspondingly, six loading conditions were feasible through this well-designed loading system. The angle between each loading direction was $18^{\circ}$. All the accessorial components were manufactured by steel. Comparing with the FRP composites and adhesive materials, the deformation of steel components can be neglected during tests, due to the high stiffness of steel material.

\section{Experimental Investigation}

\subsection{Specimen preparation, loading device and measurements}

In this study, the FRP-to-steel adhesivelybonded joints were experimentally investigated under tensile and shear loading. The test set-up was shown in Fig. 5. Load was applied from a servohydraulic actuator, the SCHENCK Hydropuls testing machine with a capacity were performed under LVDT(linear variable differential transformer)-control in an ambient environment. Two LVDTs were assigned on each side of the loading system, as shown in Fig. 5, to measure the displacement between the top and bottom loading device.

What is more, displacement sensors were assigned on both sides of adhesive joints, to track the relative deformation between FRP sandwich deck and steel support during the whole test process, as shown in Fig. 6 . For the tensile loading condition, three displacement sensors were assigned on each side of adhesive joint, while two displacement sensors for shear loading condition. Six replicated specimens were prepared for each loading condition. Before gluing, three of specimens were pretreated on the surfaces of FRP sandwich deck and steel supports by using sandpapers and acetone. For comparison, the other three specimens were glued without any surface pretreatment. The surface pretreated specimens were indicated as SP-specimens in the following chapters, and un-pretreated specimens were described by UP-specimens. 


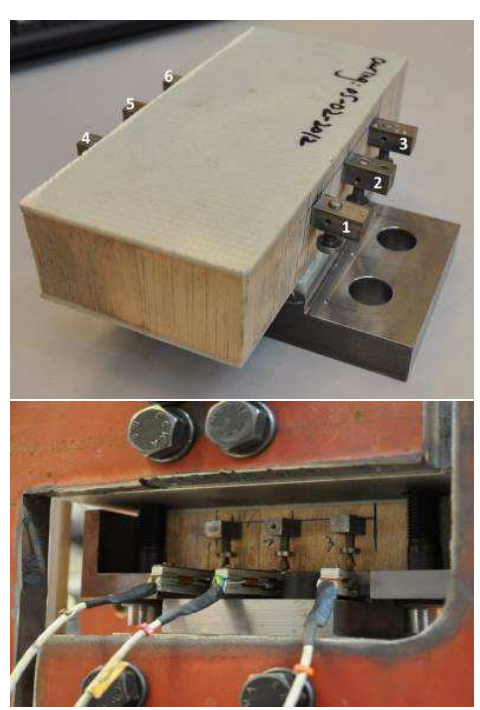

a) tensile loading

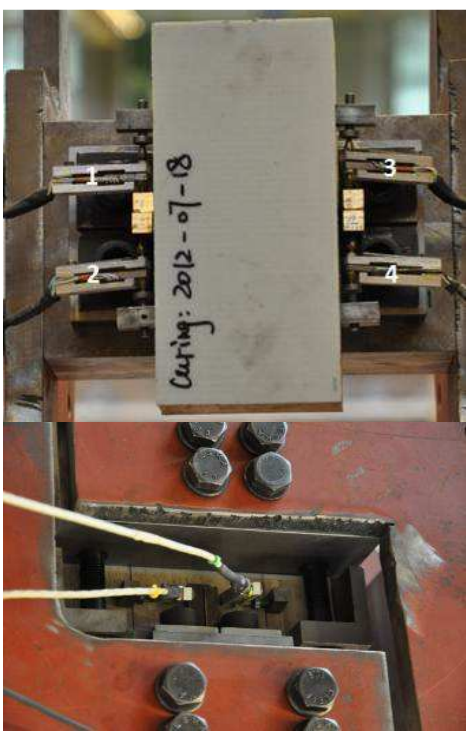

b) shear loading

Fig. 6 Assignment of displacement sensors

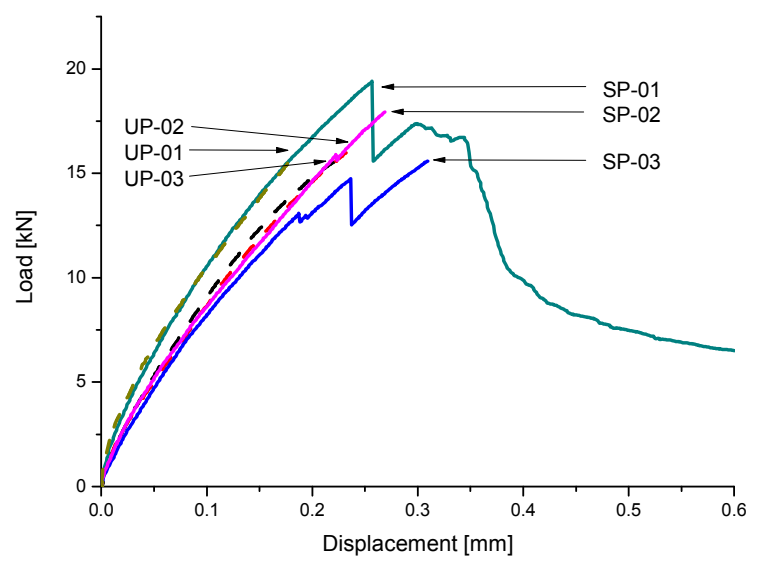

Fig. 7 Load-displacement curves

\subsection{Results and discussion}

\subsubsection{Tensile loading}

For the UP-specimens, the loads increased almost linearly up to failure. The ultimate failure of three specimens always occurred in a brittle and sudden manner, through the bondline between FRP laminates and adhesive layer. As listed in Table 1, the average ultimate failure load was 16.05 $\mathrm{kN}$, the deviation from the three specimens was $2.37 \%$. Fig. 7 shows the load-displacement curves of adhesive joint specimens, which were measured by the LVDTs. It is manifest that the curves from UP-specimen 02 and UP-specimen03 agree well with each other. But for the UPspecimen 01 , the stiffness is a bit different from the other two, which could be due to the deviation of material properties and quality of gluing between FRP sandwich deck and steel support. What is more, it is obvious that the three curves are almost parallel to each other in the stable load increasing stage. It can be explained that at the beginning of loading, the friction between each component of loading device made the initial stiffness of specimens different from each other. However, when the loading was large enough beyond the friction, the stiffness of three adhesive joints was approximately the same.

Fig. 8 shows the measurement of vertical deformation between FRP sandwich deck and steel support on the UPspecimen02 from six displacement sensors. It can be clearly seen that the measured data from displacement sensors DS-01, DS-03, DS-04

and DS-06 are close to each other, while the deformation from DS-02 and DS-05 are relatively smaller. It implies that the edge part of bonding area deformed larger than the middle part. However, the total deformation through the adhesive joint was in a very small scale, with the order of magnitude $0.01 \mathrm{~mm}$. Fig. 8 also shows that, besides the pure tensile loading, a certain amount of additional bending moment was also applied during the whole testing process, with the deformation from DS-04, DS-05 and DS-06 a little larger than that of DS-01, DS-02 and DS-03. It means the loading was not applied centrically on the adhesive joint. What is more, the minus values of DS-02 implies that the middle part of adhesive joint at the right side was already under compression for the last stage of loading. Test results on other UP-specimens present similar mechanical behaviours in the vertical direction of adhesive joint. Such an additional bending moment induced by eccentric loading cannot be avoided in such a small scale test. Furthermore, the vertical deformation between 
FRP sandwich deck and steel support was not increasing linearly during the whole test, especially for DS-02, DS-03 and DS-05. This indicates that stress redistribution occurred through the adhesive joint when the applied load was approaching to the failure load.

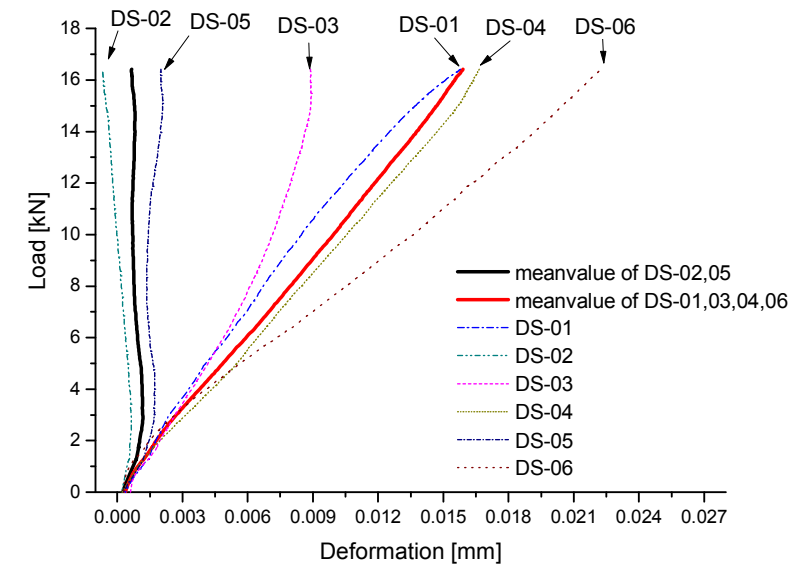

Fig. 8 Load-deformation curves measured from six vertical displacement sensors on the UPspecimen02 ( $D S=$ displacement sensor)

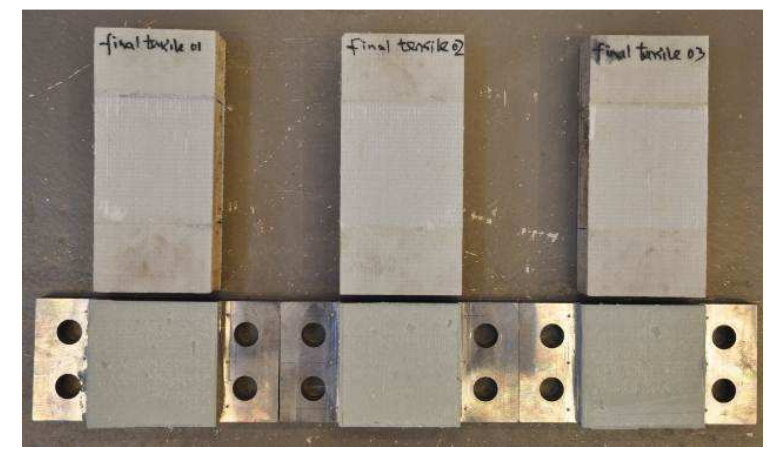

a) Failure modes of UP-specimens

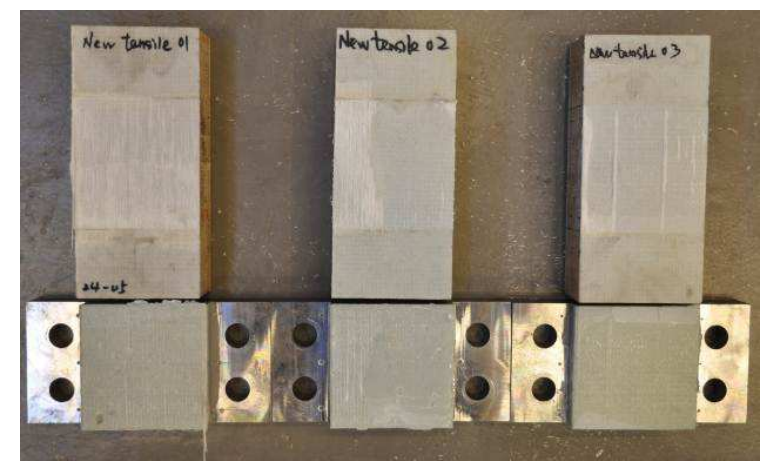

b) Failure modes of SP-specimens

Fig. 9. Failure modes of adhesive joints

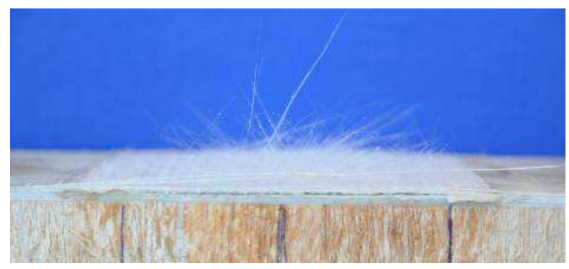

Fig. 10. Delamination failure
For the SP-specimens, as shown in Fig. 7, the similar stiffness with that of UPspecimens were achieved. There was the sound warning from fibre breaking, when loads approaching the ultimate failure load. Fig. 9 shows the failure modes of SPspecimens comparing with UP-specimens. It can be clearly observed that the failure plane for un-pretreated adhesive joint was through the interface between the FRP sandwich deck and adhesive layer. However, for the SP-specimens, the failure plane partly moved to the delamination of FRP composites, as shown in Fig. 10, where broken fibers and delamination through FRP laminates were obvious for SP-specimen01. That is why there was some residual load-bearing capacity after the maximum failure load achieved, presented by the load-deformation curves shown in Fig. 7. As shown in Table 1, the average ultimate failure load of SP-specimens was $17.62 \mathrm{kN}$, which was $9.83 \%$ higher than that of UP-specimens. While the deviation of failure loads were larger than that of UPspecimens. It means that the surface pretreatment contributes less to stiffness increase of adhesive joint, but can improve the bonding quality between FRP composites and adhesive layer, correspondingly increasing the strength of the whole adhesive joint under tensile loading. It also indicates that the through-thickness strength of FRP laminates was a little higher than bonding strength of the adhesive-adherend between FRP laminates and adhesive layer. What is more, from Fig. 9b), it can be found that the areas of FRP delaminated parts are different among SP-specimens. SPspecimen01 attained the largest FRP delaminated area which almost covered the whole bonding area; while SP-specimen03 attained the smallest, which can be considered as no contribution from surface pretreatment, since the failure load of SP-specimen03 was $15.57 \mathrm{kN}$, even lower than any failure load of UP-specimens. Thus, it can be found that the delaminated area of FRP composites is the direct factor influencing the final strength of adhesive joint under tensile loading. That is why the SPspecimen 01 owned the maximum ultimate failure load.

\subsubsection{Shear loading}




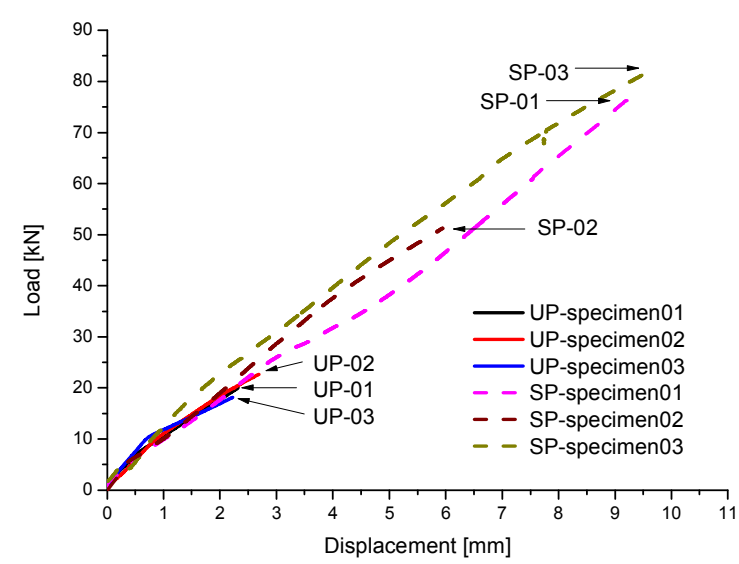

Fig. 11 Load-displacement curves

Table 2. Ultimate failure loads of six adhesive joints

\begin{tabular}{lccccc}
\hline & UP-01 & UP-02 & UP-03 & Average & Deviation \\
\hline Failure load (kN) & 18.1 & 25.0 & 22.7 & 21.9 & $17.5 \%$ \\
\hline & SP-01 & SP-02 & SP-03 & Average & Deviation \\
\hline Failure load (kN) & 76.4 & 51.2 & 82.4 & 70.0 & $26.9 \%$ \\
\hline
\end{tabular}
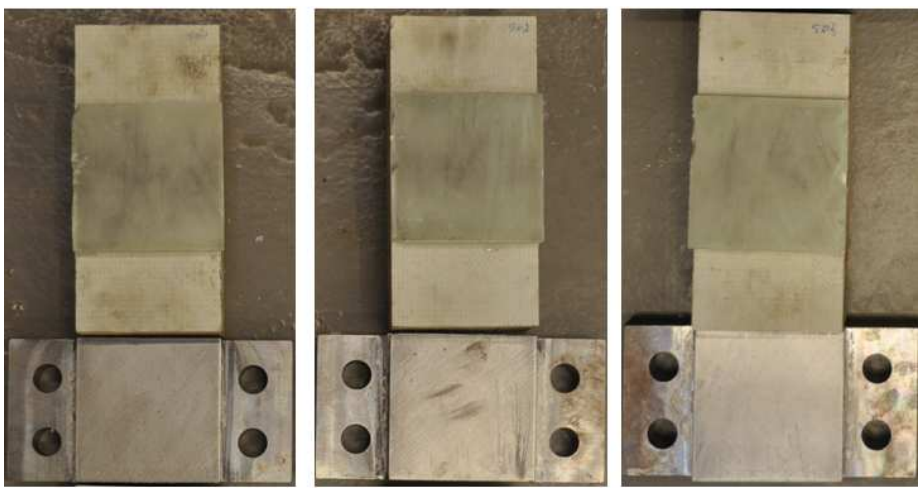

a) Failure modes of UP-specimens
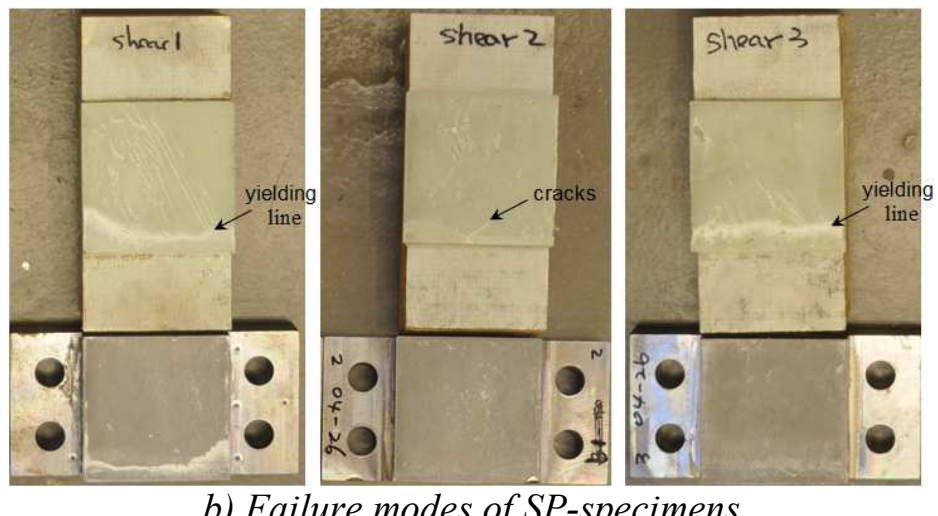

b) Failure modes of SP-specimens

Fig. 12. Failure modes of adhesive joints
For both SP-specimens and UP-specimens under shear loading, the loads increased almost linearly up to failure. The ultimate failure of adhesive joints always occurred in a brittle and sudden manner, without any visible signs or sound warning from fiber breaking. Fig. 11 shows the load-displacement curves of all six specimens, which are the average values measured by the LVDTs. It implies that UPspecimens and SP-specimens agree well with each other for the slopes of curves, which reconfirms that stiffness of adhesive joints hardly relates to surface pretreatment methods. However, for the ultimate failure loads, as listed in Table 2, the average ultimate failure load of $\mathrm{SP}$-specimens is $70 \mathrm{kN}$, which is more than three times of that of UPspecimens.

Fig. 12 shows the failure modes of UP-specimens and SP-specimens. From SP-specimen01 and SPspecimen03, the yielding line (white-color line across the section) present on the surface of adhesive layer, at a small distance away from the adhesive bottom edge. Both yielding lines locates approximately at the same place. However, for the SPspecimen 02 , there is no obvious yielding line founded. Instead, some cracks can be clearly seen at the area close to adhesive layer edge. Thus, the lower load-bearing capacity achieved by SP-

speicmen02 can be attributed to its failure mode. Cracks were initiated by the stress concentration at the non-homogenous area of adhesive material, which induced the premature failure of adhesive joint. This exception increased the deviation of three specimens to $26.9 \%$. While, the deviation of failure loads between SPspecimen 01 and SP-specimen03 was only $7.9 \%$. Regarding to UPspecimens, the failure plane moved from adhesive layer to the interface between adhesive layer and steel

support, which was commonly termed as adhesion failure. This failure mechanism was due to lacking of sufficient surface pretreatment on steel support. From the failure surface of adhesive layer, as shown in Fig. 12a), it is clearly be seen that the rust (dark-color stuff) was torn out from steel surface and left on the adhesive surface. Fig. 13 and Fig.14 clearly shows the different failure modes between SP-specimens and UP-specimens, from the view of steel support surface. The 
adhesive joints without surface pretreatment lead to extremely lower values of ultimate failure loads, as aforementioned, less than one-third of SP-specimens. Consequently, the conclusion can be drawn that, also for the specimens under tensile loading, it is of great important to execute the sufficient surface pretreatment on both FRP sandwich deck and steel girder in practice to confirm the reliable mechanical performance of adhesive joints between them. Furthermore, it would be perfect if the quality of surface pretreatment can be evaluated, of instance, by measuring the surface roughness.

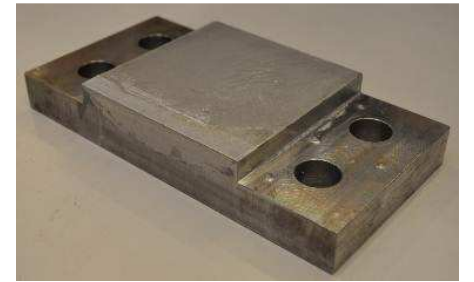

Fig.13. adhesive failure of SP-specimens

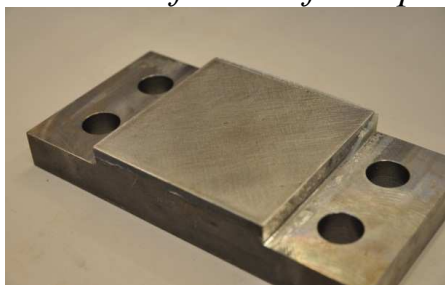

Fig. 14. adhesion failure of UP-specimens

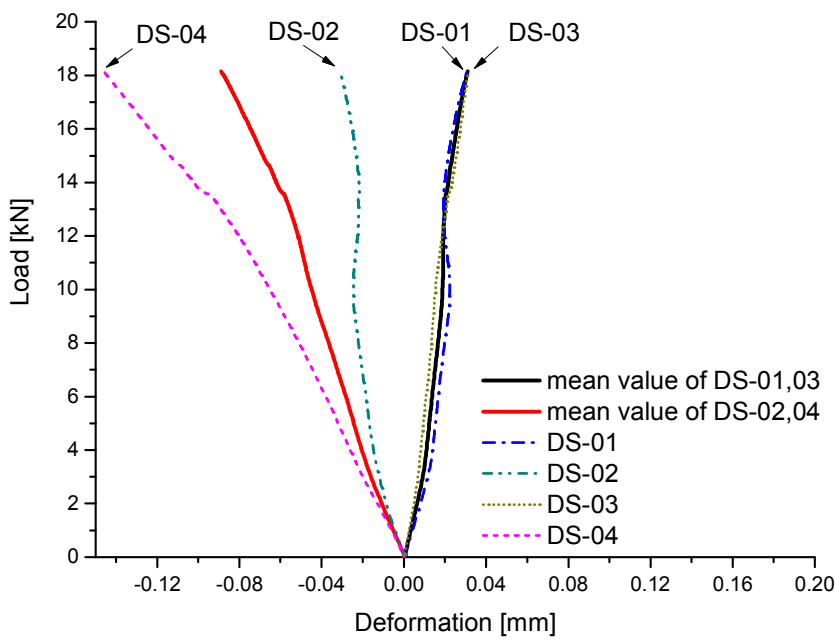

Fig. 15 Load-deformation curves measured from six vertical displacement sensors on the UP-specimen02 ( $D S=$ displacement sensor)
Fig. 15 shows the measurement of relative deformation between FRP sandwich deck and steel support on the UP-specimen01 from four displacement sensors. It can be found that the measured deformation from DS-02 and DS-04 deviated each other, which indicated that the shear force were not loaded centrally, but slightly concentrated on the DS-04 part. However, for the displacement sensors DS-01 and DS-03, the measured deformation were very close to each other, indicating that the load were balanced on two sides of specimen, at far end of adhesive joint from the loading edge. The values were less than half of the absolute deformation values from DS-02 and DS-04. What is more, all the load-deformation curves were not increasing linearly, since the stress state in adhesive layer kept redistributing during the whole test process, which was due to the nonhomogeneous property of adhesive layer. From the failure surface of adhesive layers, pores was easily observed. Test results on other UP-specimens and SP-specimens presented similar mechanical behaviours regarding to relative deformation between FRP sandwich deck and steel support. The eccentric loading cannot be avoided in such a small scale test. Further stressstrain analysis on the adhesive joint will be conducted by Finite Element analysis to understand the stress-strain distribution across the interface between adhesive layer and steel support, since it is not possible to track the strain distribution in the experiments.

\section{Conclusion}

In this paper, FRP sandwich deck to steel support adhesively bonded joints were experimentally investigated under both tensile and shear loading condition. The mechanical behaviour of adhesive joint specimens with surface pretreatment (SP) and without surface pretreatment (UP) were compared for these two loading case. All of adhesive joint specimens failed in a sudden and brittle method, expect that a lightly extent of ductility was evident for SP-specimen under tensile loading. The surface pretreatment dominated the failure modes and ultimate failure load of adhesive joint, but not the stiffness of adhesive joints. For tensile loading condition, the failure mode was moved from the adhesion failure between FRP laminates and adhesive layer (UP-specimen) to FRP delamination (SP-specimen). The ultimate failure load of UP-specimens was $16.05 \mathrm{kN}$, which was increased to $17.62 \mathrm{kN}$ by the surface pretreatment. For shear loading condition, the failure mode was moved from adhesion failure between adhesive layer and steel support (UP-specimen) to adhesive failure in the adhesive layer (SP-specimen). The ultimate failure load of UP-specimens was only $21.9 \mathrm{kN}$, which was less than one-third of that of SP-specimens $(70 \mathrm{kN})$. Therefore, sufficient surface 
pretreatment on FRP sandwich decks and steel girders must be satisfied in practice, to improve the mechanical performance of the adhesively bonded joints under tensile and shear loading.

Furthermore, it can be found that the strength of adhesive joints under tensile loading was lower than that under shear loading (26.7\% lower for UP-specimens and $74.8 \%$ for SP-specimens). It indicates that the failure of adhesive joint was initiated more easily by the through-thickness stress. Further research will be followed by the tensile-shear interacted loading conditions and Finite Element modelling. The failure criterion of adhesive joints is expected to be drawn, which can be employed to predict the strength of adhesive connection between FRP decks and steel girder under other combination of shear and tensile loads.

\section{Acknowledgements}

The authors would like to thank Infra Composites B.V. for financial support and supplying the FRP sandwich deck of this research.

\section{References}

[1] KNIPPERS J., PELKE E., GABLER M., BERGER D., "Bridges with Glass Fibre-Reinforced Polymer Decks: The Road Bridge in Friedberg, Germany", Structural Engineering International. Vol. 20, No.4, 2010, pp. 400-4.

[2] SEBASTIAN W.M., ROSS J, KELLER T, LUKE S. "Load response due to local and global indeterminacies of FRP-deck bridges". Compos Part B-Eng. Vol. 43, No.4, 2012, pp. 1727-38.

[3] LUKE S., CANNING L., COLLINS S., KNUDSEN E., BROWN P., TALJSTEN B., ET AL. "Advanced composite bridge decking system-project ASSET". Structural Engineering International. Vol. 12, No.2, 2002, pp. 76-9.

[4] CAMATA G. and SHING P.B., "Static and fatigue load performance of a gfrp honeycomb bridge deck". Compos Part B-Eng. Vol. 41, No.4, 2010, pp. 299-307.

[5] KELLER T. and VALLEE T., "Adhesively bonded lap joints from pultruded GFRP profiles. Part I: stress-strain analysis and failure modes". Compos Part B-Eng. Vol. 36, No.4, 2005, pp. 33140.

[6] KELLER T. and VALLEE T., "Adhesively bonded lap joints from pultruded GFRP profiles. Part II: joint strength prediction”. Compos Part B-Eng. Vol. 36, No.4, 2005, pp. 341-50.

[7] VALLEE T. and KELLER T., "Adhesively bonded lap joints from pultruded GFRP profiles. Part III: Effects of chamfers”. Compos Part B-Eng. Vol. 36, No.4, 2005, pp. 328-36. 